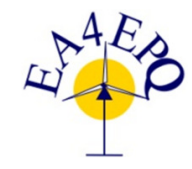

International Conference on Renewable Energies and Power Quality (ICREPQ'13)

Bilbao (Spain), 20 ${ }^{\text {th }}$ to $22^{\text {th }}$ March, 2013

Renewable Energy and Pourer Quality. Fournal (RE\&PQJ)

ISSN 2172-038 X, No.11, March 2013

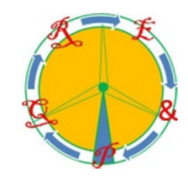

\title{
Wind Power Determination for Maximum Power Point Tracking in Lab-scale Multi-MW Wind Energy Systems
}

\author{
Gregorio Martínez ${ }^{1}$, Luis Parras ${ }^{1}$, Mario J. Durán ${ }^{2}$ and C. Pino ${ }^{1}$ \\ ${ }^{1}$ Department of Fluid Mechanics \\ E.T.S.I.I., University of Málaga \\ C/ Doctor Ortiz Ramos S/V, 49071 Málaga (Spain) \\ Phone/Fax number:+0034 951952383, e-mail: Iparras@uma.es \\ ${ }^{2}$ Department of Electrical Engineering \\ E.T.S.I.I., University of Málaga \\ C/ Doctor Ortiz Ramos S/V, 49071 Málaga (Spain) \\ Phone/Fax number:+0034 951952360, e-mail: mjduran@uma.es
}

\begin{abstract}
The low voltage ride through (LVRT) grid code requirements are pushing the new era of multi-MW wind energy conversion systems (WECS) to full-power topologies. Lab-scale emulation of such multi-MW systems usually substitutes the wind energy conversion by a torque-producing emulator (e.g. DC machine). Nevertheless, the complete study of the wind energy system is more insightful and allows a better analysis of the WECS. This work focuses on the design of the blades and the wind power calculation for lab-scale emulation of multi-MW wind energy systems. Theoretical analysis for the design of the lab-scale system is presented and experimental results show the wind power characteristic curves for maximum power point tracking of variable-speed generators.
\end{abstract}

\section{Key words}

Wind energy systems, blade design, maximum power point tracking, full-power system.

\section{Introduction}

The global wind power installed capacity has exponentially increased in the last decade to reach $238 \mathrm{GW}$ by the end of 2011 [1]. As the technology of wind energy conversion systems (WECS) becomes mature, emerging markets increase their investments (e.g. China accounts for $43 \%$ of global new installed capacity in 2011) and the wind share of total electricity consumption (e.g. $25.9 \%$ in Denmark) makes the wind industry a major actor in the energy mix [2]. Along with this growth rate, grid codes are worldwide becoming tighter [3]-[4] and low voltage ride through (LVRT) requirements are pushing the technology forward to achieve a higher degree of control [5]-[6]. Even though partial-power wind energy systems based on doubly-fed induction generators (DFIGs) is still the most installed configuration, many manufacturers are implementing full-power topologies in their new models in order to fully comply with grid code requirements [5].
Additionally, offshore wind farms are also increasing their role in the European market. For the sake of example, 132 offshore wind turbines with a combined capacity totalling 523.2 MW were installed and fully grid connected in Europe during the first six months of 2012 [7]. Offshore locations require wind turbines with increased rated power (up to $10 \mathrm{MW}$ so far [8]) in order to benefit from the economy of scales. Nevertheless, the increased size and power of modern wind turbines requires the use of parallel devices in order to deliver the full power to the grid.

In this context of higher-power wind turbines and fullpower topologies, the use of multiphase generators shows a good prospect for industrial applications because the power is inherently split and the additional phases allow some extra benefits [9]. For example, Spanish manufacturer Gamesa has developed a full-power 4.5 MW wind turbine with 6 parallel converters and 18 phases [10]. Some other topologies that use series connected generator-side converters have also been proposed to achieve medium voltage on the grid-side (Fig. 1) [11]-[12].

The design of a lab-scale full-power WECS similar to that of Fig. 1 becomes a highly complex and multidisciplinary task. For this reason, many researchers have focused their investigations on the electrical energy conversion and have replaced the wind turbine by an electrical machine that emulates the wind torque on the shaft [9],[13]. The studies combining the wind turbine performance together with the electrical energy conversion are very scarce. However, the development of the whole lab-scale system is more insightful and allows approaching the problem from different and multidisciplinary points of view. This work concentrates on the design and characterization of the wind turbine (marked in dotted line in Fig. 1) while subsequent studies will address the rest of the wind energy system. 


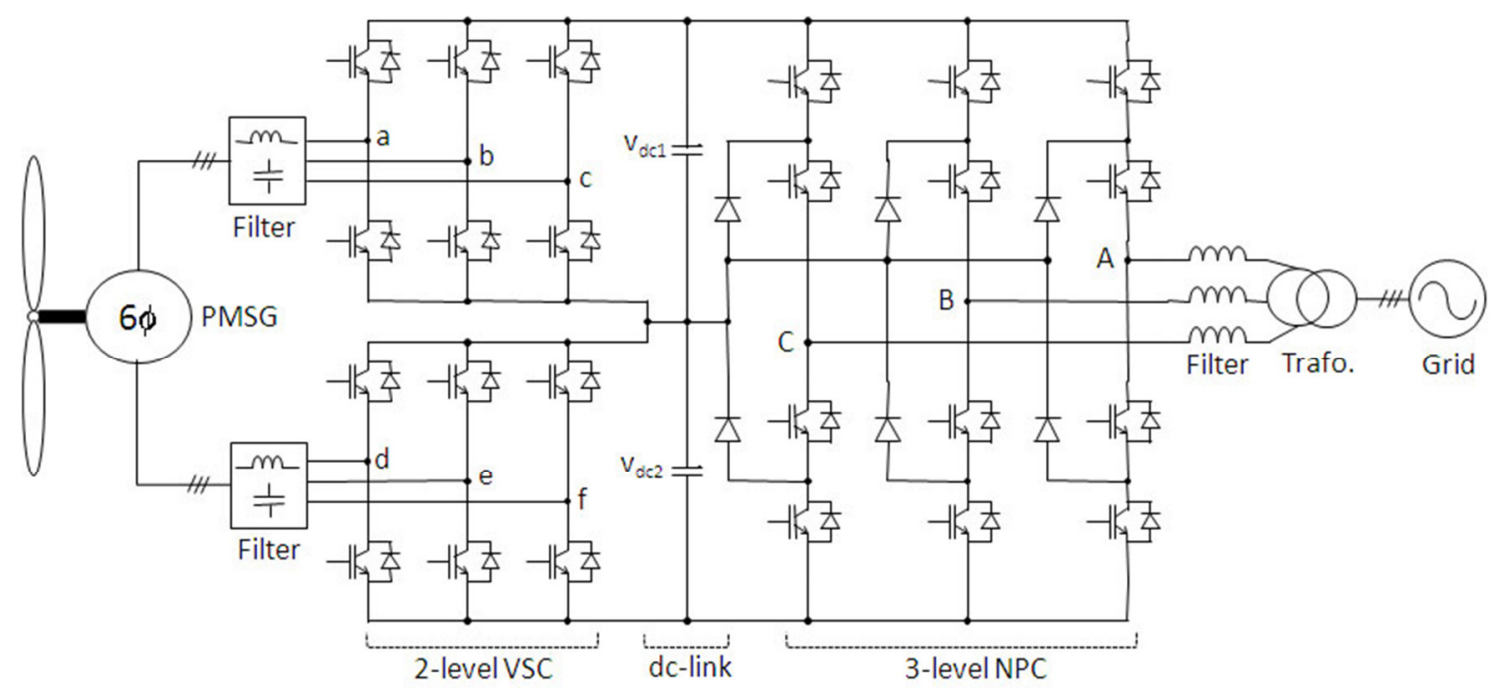

Figure 1. Wind energy conversion system with series-connected generator-side converters.

As far as the wind turbine is concerned, the challenge is to make a lab-scale design that resembles the performance of the multi-MW wind energy systems. The control of the wind generator will use a maximum power point tracking (MPPT) algorithm to extract the maximum energy from the wind [5], but it is firstly necessary to design the blades and determine the achievable wind power. Two restrictions are imposed for the design: the size of the wind tunnel, which will fix the length of the blades, and the fact that the same generator will be used later on for control purposes.

Wind turbine design is typically done using the Blade Element Method (BEM) [14]-[15]. This is a one dimensional model with experimental corrections for wing tip losses, 3D effects, stall corrections, etc. This model basically uses typical wing profiles used in aeronautics as wind turbine blades. Once the model is designed, there are few tests in wind tunnels, at least for lab models of large wind turbines (wind tunnel tests of small scale turbines can be found in [16]). Large scale turbines have been recently tested in large wind tunnels under controlled conditions [17]-[18], providing a database for future modelling and design.

The paper is organized as follows. Section II presents the design of the blades and mechanical structure for the labscale prototype. Section III discusses the MPPT algorithms and details the experimental set up used to obtain the wind power from the designed prototype. Section IV presents and discusses the experimental results and section $\mathrm{V}$ finally draws some conclusions.

\section{Prototype design}

The aim of this paper is to design, build and test a wind turbine similar to the final multi-MW wind energy system. In fluid mechanics, similarity holds whenever all the nondimensional parameters of both the real and scaled wind turbines are the same. In this case, the nondimensional parameters that control the problem are the Reynolds number $R e$, that measures the ratio between inertia and viscous forces, and the tip speed ratio (TSR), that measures the ratio between the blade tip velocity and the wind speed. The length scale will be the blade radius $R$ and the characteristic velocity of the wind speed $U$. The real model that has been taken as reference is the wind energy conversion system described in [19]. It has a radius of $R_{l}=30 \mathrm{~m}$, rotates at $\Omega_{l}=12.1 \mathrm{rpm}$ and the rated wind speed is $U_{l}=11.4 \mathrm{~m} / \mathrm{s}$. Due to the size of the wind tunnel, the blade length will be $\mathrm{R}_{2}=0.3 \mathrm{~m}$. The Reynolds number and TSR are defined as:

$$
\begin{aligned}
& R e_{i}=\frac{\rho U_{i} R_{i}}{\mu} \\
& T S R_{i}=\frac{\Omega R_{i}}{U_{i}}
\end{aligned}
$$

To force the Reynolds number to be equal in both cases, the wind speed needs to be set to:

$U_{2}=\frac{R_{1}}{R_{2}} U_{1}=1440 \mathrm{~m} / \mathrm{s}$

This velocity is far from the maximum attainable by the wind tunnel, mostly due to the change of size between the model and the real wind turbine. That is the reason why some more accurate tests have been done in wind tunnels with bigger test sections $(24 \mathrm{~m}$ by $36 \mathrm{~m}$ of test section in [17] and $9.5 \mathrm{~m}$ by $9.5 \mathrm{~m}$ in [18]). In this wok only the TSR will be the same in both turbines. In any case, this assumption is realistic because the wind loading over the blades depends very little on the Reynolds number for the wing profile used, provided it is high enough.

Another important constraint in the design of the scaled laboratory model is that it should provide at least $1 \mathrm{~kW}$, so that the gap between the power of the real (multi-MW) and lab-scaled wind turbines is limited. In order to estimate the wind speed that would be required to achieve such power, the Betz criterion, which fixes the maximum energy that can be extracted from a wind turbine of radius $R_{2}$ with a wind speed of $U_{2}$, is used:

$P_{\text {Betz }}=\frac{16}{27} \frac{\rho}{2} U_{2}^{3} \pi R_{2}^{2}$

and then $U_{2}=21.5 \mathrm{~m} / \mathrm{s}$. 
Imposing the maximum velocity that can be obtained by the wind tunnel $U_{2}=21.5 \mathrm{~m} / \mathrm{s}$, and making both TSR equal $(\mathrm{TSR}=3.33)$, one gets the rotational speed that needs to be used in the model to obtain a correct scaling:

$\Omega_{2}=\frac{R_{1} U_{2}}{R_{2} U_{1}} \Omega_{1}=2175 \mathrm{rpm}$

Even though this value is quite high, it is expected to have a power production of around $1 \mathrm{~kW}$ if rotation speeds of that order are achieved.

The blade profile of the real turbine is required to compare the results of the real wind turbine. Since the blade data were not available, a new design of the blades has been done in this work (See Fig. 2). The Blade Element Method (BEM) is used for that purpose taking the wing profile FX08S176 as a reference. This profile has a ratio of lift coefficient and drag coefficient equal to $\varepsilon=$ 175 for a given attack angle and $\alpha=4^{\circ}$, and their corresponding values of $\mathrm{CL}=1.05$ and $\mathrm{CD}=0.006$.

One of the constraints in the design is the use of the same generator both for wind power determination and later generator control. Since the $1 \mathrm{~kW}$ wind generator was too bulky to be located inside the nacelle, the generator was fixed outside the wind tunnel using a transmission belt to connect the rotor axis with the generator axis as it is shown in the sketch of Fig. 3 (a) and in the final lab model fixed in the wind tunnel in Fig. 3 (b).

Instead of using the typical cylindrical tower to fix the wind turbine to the tunnel, a custom made structure has been used to allow enough space for the belt. Finally, the blades were made in fibre over a cast, but only the upper surface of the blade was accurately modelled.

\section{Experimental set-up}

The facility used is the wind tunnel in the Aerohydrodynamics Laboratory of the University of Malaga. It is a closed loop wind tunnel that has a test section of $1 \mathrm{~m}$ by $1 \mathrm{~m}$ and $5 \mathrm{~m}$ long. The maximum air speed is $40 \mathrm{~m} / \mathrm{s}$. The size of the test section has constrained the size of the model as it has been previously discussed. Typically in literature, models are tested in big wind tunnels of test section wider than $2 \mathrm{~m}$ (see [16], [17]).

Since the aim of the experimental setup is to determine the wind power, there is no need to provide a converterbased control and it is enough to connect the wind generator to a set of three-phase resistances. Consequently, the experimental rig for the wind power determination is not grid-connected and thus requires a synchronous generator (induction generator would need reactive power from the grid or a capacitor bank). The synchronous generator is fed from a rectifier and a transformer that is connected to the grid. The power generated by the synchronous generator is dissipated by the variable threephase resistances whose values can be changed to obtain different operation points of the wind energy system. A detailed scheme of the experimental rig with all measurement devices is shown in Fig. 4.

In the experimental setup it is possible to measure the active power in the resistances and thus determine the wind power for different wind and turbine speeds.
This wind power determination is the basis for the maximum power point tracking (MPPT) algorithm that will need to be performed in the machine-side control of a full-power wind energy system with back-to-back converters (Fig. 5). In standard variable-speed drives the speed/torque reference is directly set but in wind energy conversion systems the generator speed is dependent on the measurement of the wind speed. The final control of the machine-side thus includes a flux control and a speed/torque control that guarantees the extraction of the maximum active power using the MPPT curves that are determined in this work. The control scheme shown in Fig. 5 is planned to be implemented once the experimental rig of the full system shown in Fig. 1 is built. The experimental results obtained using the rig shown in Fig. 4 and the maximum power point determination are now examined in the next section.

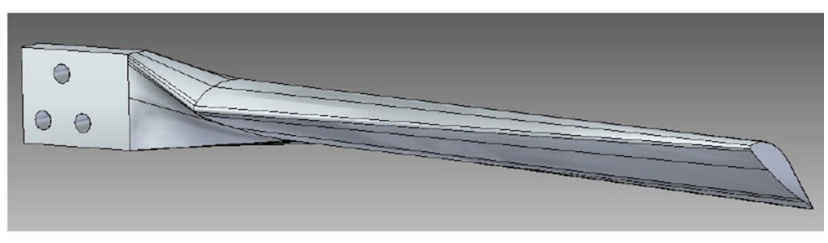

(a)

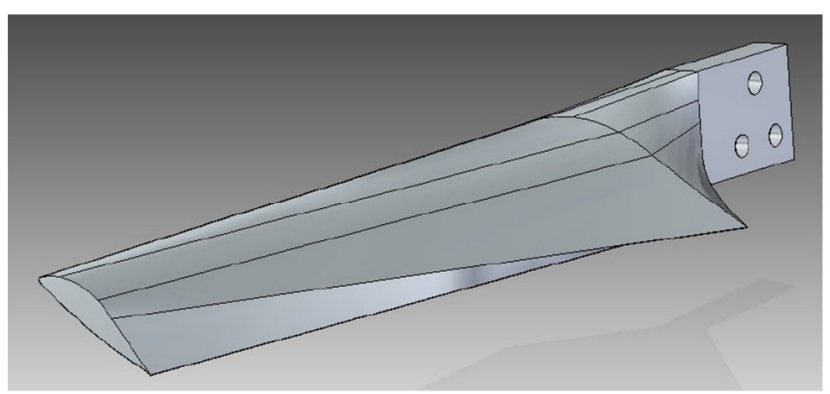

(b)

Figure 2: Front (a) and rear (b) views of the designed blade.
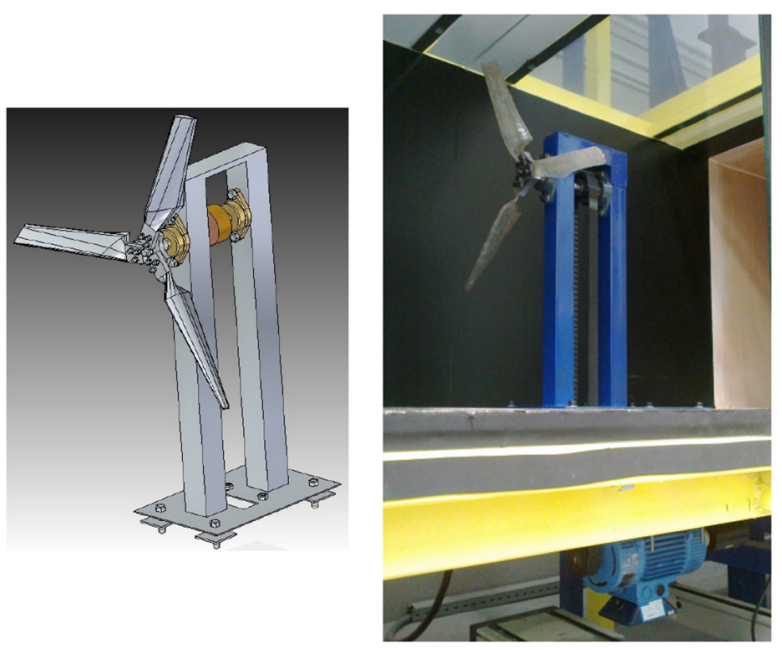

(a)

(b)

Figure 3: CAD sketch of the lab model (a) and the final installation in the wind tunnel (b). In this case it can be observed the transmission belt and the generator fixed outside the wind tunnel. 


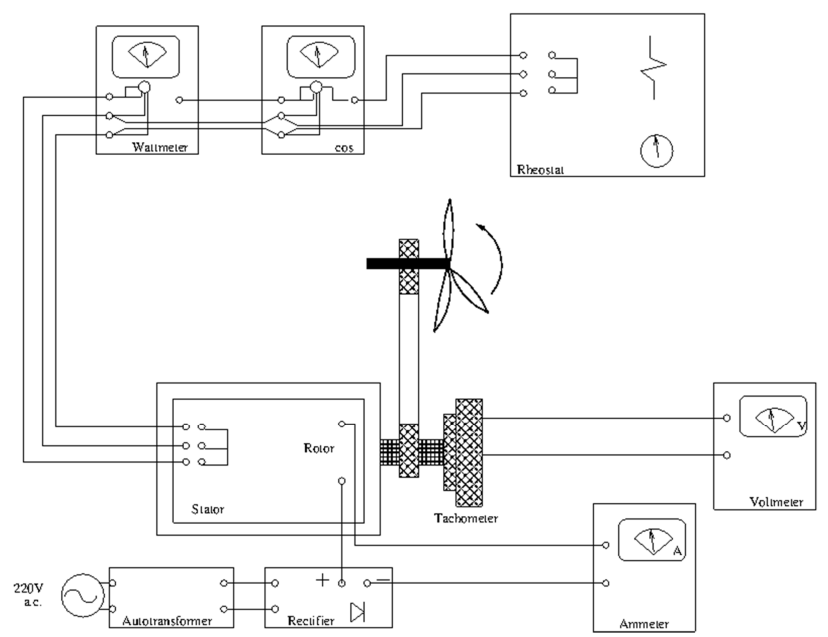

Figure 4: Outline of the experimental rig used for the calculation of the generated wind power at different speeds.

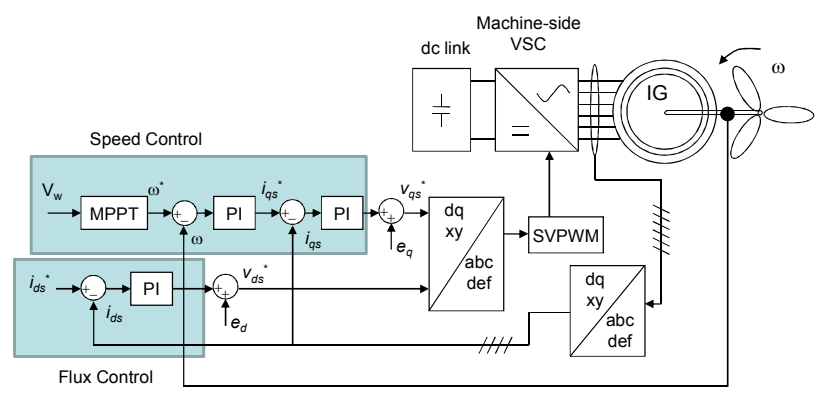

Figure 5: Scheme of the machine-side control in wind energy systems with full-power topology including maximum power point tracking (MPPT).

\section{Experimental results}

The final results are shown in this section. For a given velocity of the wind tunnel, the value of the resistor is changed and the turbine rotates at different rotation speeds. The results shown in Fig. 6 are obtained if the same procedure is repeated for different wind velocities. In this figure it is shown the power generated versus the generator speed for different wind speeds. The interpolated maximum of each velocity field is marked with stars, this being the main information (the results of power, velocity and rotation speed for this maximum) to generate the MPPT algorithm shown in Fig. 5. Plotting the corresponding maximum power $\left(P_{\max }\right)$ at the corresponding generator speed where that maximum is located, the maximum power (shown in Fig. 7) is defined by the relation:

$$
P_{\max }=1.6536 \mathrm{e}-05 \omega_{\max }^{-2.61}
$$

On the other hand, representing the generator speed versus the wind speed, one obtains the expected rotation speed for the MPPT algorithm for each wind speed velocity (see Fig. 8).
They are linearly related:

$\omega_{\max }=15.8852 V_{\max }-139.58$

As it can be seen in figures 6 and 7, the real maximum power generated is far from the expected design. The main reason for this is that the wind turbine is not rotating at the designed TSR. In the point of maximum generated power the TSR is roughly 0.5 instead of 3.33 . To check if the experimental model performs according to the design, the expected power coefficient $C p$ (ratio between the real power and the maximum power contained in the wind) has been calculated. This coefficient is shown in Fig. 9, where the stars are the experimental values for different TSR The values of $C p$, calculated by BEM theory, are also depicted in Fig. 9 using solid line. As it can be seen, real results show that there is a minimum TSR to rotate. This means that for a given wind speed there is a start-up rotation speed below which, the prototype is unable to generate power. In dashed lines it is shown the BEM theory displaced to take into account this start-up TSR.

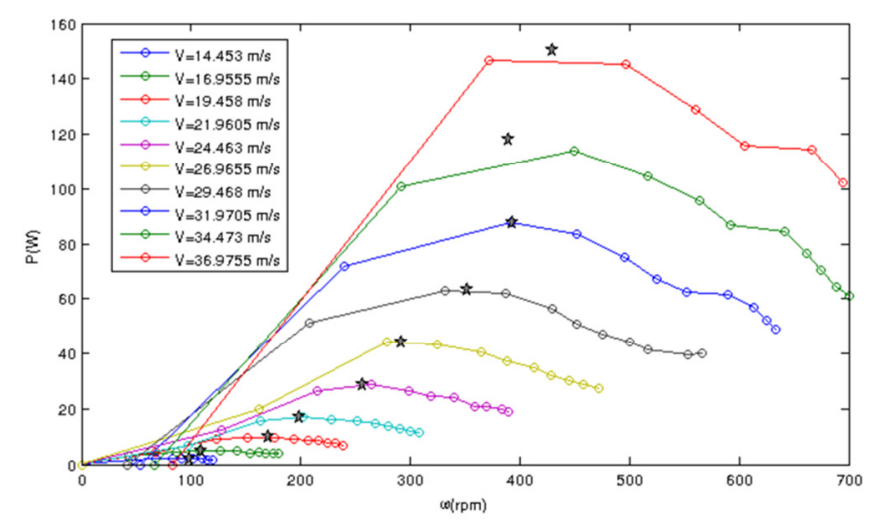

Figure 6: Power generated by the lab wind turbine for different wind tunnel velocities. Interpolated maxima for each curve are denoted with stars.

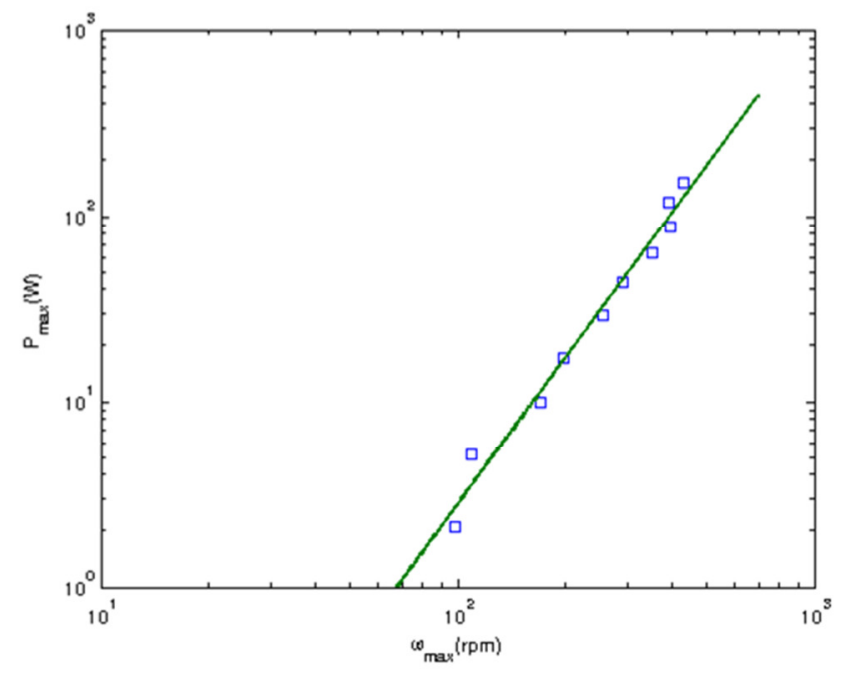

Figure 7: Maximum power generated by the lab wind turbine for the corresponding generator speed where the maximum appears, for each wind velocity. 


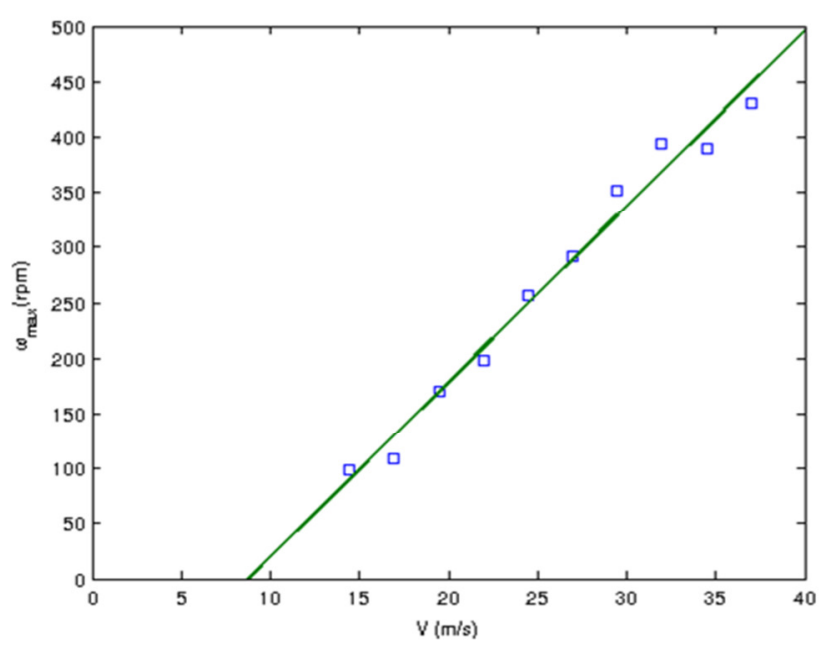

Figure 8: Generator speed to get the maximum power generation.

These theoretical results (dashed line) match the experimental results (stars) and confirm the ability of BEM to accurately predict the blade performance in the energy conversion process.

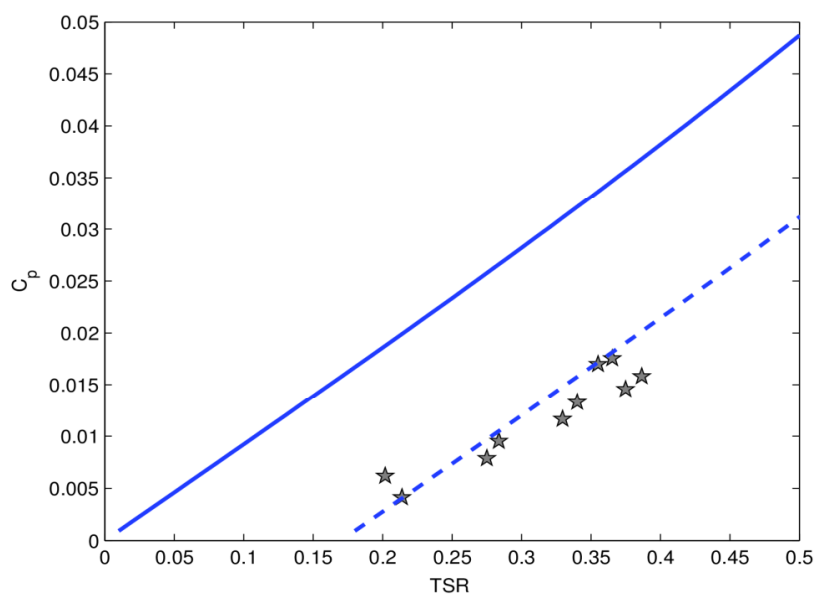

Figure 9: Experimental power coefficient $C p$ for the model (stars) for the different TSRs obtained at the maximum power for each wind speed. In solid line are shown the BEM theory results. In dashed line it is shown the theory overlapped with the experiment.

Former results show that the design is properly done, but the generator is unable to rotate at the rated speed for a given wind speed. This can be due to the transmission between the axis of the turbine and the generator and the losses of the generator that it is rotating far away from the rated speed.

\section{Conclusions}

Even though multi-MW wind energy systems are currently intensively investigated, the problem of the blades design and wind power determination for lab-scaled low-power systems has not been properly covered so far. This works provides some guidelines to design lab-scaled blades with the aim to reproduce the behaviour of multiMW systems. Although the blades can be designed using standard blade element method, it is shown that it is necessary to consider operating conditions that simultaneously reproduce the multi-MW system with a range of power, wind speed and turbine rotation that can be implemented in a low-power lab. Results of the measurements show standard relationships between power.
Wind speed and turbine rotation that are the basis of a maximum power point tracking algorithm in a future converter-based control of the wind turbine.

\section{Acknowledgement}

The authors gratefully acknowledge the Spanish Government (National Research, Development and Innovation Plan, under project reference DPI201125396) for the financial support provided.

\section{References}

[1] Global Wind Energy Council (GWEC), "Global Wind Report. Annual Market update 2011", March 2012. Online available: http://gwec.net/wpcontent/uploads/2012/06/Annual report 2011 lowres.pdf.

[2] European Wind Energy Association (EWEA), "Wind in Power. 2011 European Statistics", Feb. 2012. Online available: http://www.ewea.org/ fileadmin/files/library/publications/statistics/Wind in power_2011_Eur opean statistics.pdf.

[3] "Grid code - high and extra high voltage," E.ON Netz Gmbh, April 2006.

[4] Red Eléctrica de España. P.O. 12.3: Requisitos de respuestafrente a huecos de tensión de las instalaciones de producción en régimen especial, BOE 24/10/06, October 2006.

[5] M. Liserre, R. Cárdenas, M. Molinas, and J. Rodríguez, "Overview of multi-MW wind turbines and wind parks," IEEE Trans. on Industrial Electronics, vol. 58, no. 4, pp. 1081-1095, 2011.

[6] B. Wu, Y. Lang, N. Zargari, and S. Kouro, "Power conversion and control of wind energy systems," IEEE Press - John Wiley and Sons, Hoboken, NJ, 2011.

[7] European Wind Energy Association (EWEA), "The European offshore wind industry - key trends and statistics 1st half 2012" July 2012. Online available: http://www.ewea.org/statistics/offshore/.

[8] Sea Titan Data Sheet. [Online]. Available: http://www.amsc.com/ documents/displaypdf.php?id=7516.

[9] Z. Xiang-Jun, Y. Yongbing, Z. Hongtao, L. Ying, F. Luguang, and Y. $\mathrm{Xu}$, "Modelling and control of a multi-phase permanent magnet synchronous generator and efficient hybrid 3L-converters for large direct-drive wind turbines," IET Electric Power Applications, vol. 6, no. 6, pp. 322-331, 2012.

[10] B. Andresen and J. Birk, "A high power density converter system for the Gamesa G10x 4,5 MW wind turbine," in Proc. European Conf. on Power Electronics and Applications EPE, CD-ROM, 2007.

[11] M. J. Duran, S. Kouro, B. Wu, E. Levi, F. Barrero, and S. Alepuz, "Six-phase PMSG wind energy conversion system based on mediumvoltage multilevel converter," in Proc. European Conference on Power Electronics and Applications EPE, CD-ROM, 2011.

[12] H.S. Che, W.P. Hew, N.A. Rahim, E. Levi, M. Jones, M.J. Duran, "A six-phase wind energy induction generator system with seriesconnected DC-links," in Proc. IEEE Power Electronics for Distributed Generation Systems PEDG, pp. 26-33, 2012.

[13] S.A. Saleh and R.Ahshan," Resolution-Level-Controlled WM Inverter for PMG-Based Wind Energy Conversion System," IEEE Trans. on Industry Applications, vol. 48, no. 2, pp. 750-763, 2012.

[14] M. O. L. Hansen, Aerodynamics of wind turbines, Earthscan, London (2012).

[15] J. N. Sorensen, Aerodynamic Aspects of Wind Energy Conversion, Ann. Rev. Fluid Mech. Vol 43, pp.427-448, 2011.

[16] M. Predescu, A. Bejinariu, A. Nedelcu, O. Mitroi, C. Nae, M.V. Pricop and A. Craciunescu, Wind Tunnel Assessment of Small Direct Drive Wind Turbines with Permanent Magnets Synchronous Generators. ICREP 2008, Santander, Spain.

[17] D. Simms, S. Schreck, M. Hand, L.J. Fingersh,NREL Unsteady Aerodynamics Experiment in the NASA-Ames Wind Tunnel: A Comparison of Predictions to Measurements. FAST AD. NREL/TP500-29494, June 2001

[18] H. Snel, J.G. Schepers, B. Montgomerie: 'The MEXICO project (Model Experiments in Controlled Conditions): The database and first results of data processing and interpretation', The Science of Making Torque from the Wind, 28-31 August 2007, Technical University of Denmark,

[19] A. W. Hulskamp, J. W. van Wingerden, T. Barlas, H. Champliaud, G. A. M. van Kuik, H. E. N. Bersee and M. Verhaegen. "Design of a scaled wind turbine with a smart rotor for dynamic load control experiments". Wind Energy (2010). 